\title{
Modern approaches to teaching Japanese at a language university
}

\author{
Zinaida Stepanova*, Galina Parnikova \\ North-Eastern Federal University, 677000, Belinskogo 58, Yakutsk, Russia
}

\begin{abstract}
Modern approaches to teaching Japanese at a language university are analyzed in the article. It has been revealed that a significant place is given to the formation of foreign language communicative competence within the framework of the issues of teaching the Japanese language. The JF Standard for teaching and assessment of Japanese language progress was developed by the Japan Foundation. It is based on the CEFR principles. It has been proved that it is required to have an idea of the Japanese lifestyle in order to implement efficient communication in the oriental language, traditions, and customs. Therefore, compulsory regional knowledge is an integral part of the foreign language training of students.
\end{abstract}

\section{Introduction}

Currently, much attention is paid to the functioning of communicative competence in the framework of the teaching issues of the Japanese language. The Japan Foundation has developed a Japanese language teaching standard (JF standard), based on the Common European Framework of Reference for Languages (CEFR) system, which is used in European teaching methods of foreign languages [1]. According to the Japan Foundation system of standards, language communication is considered as communicative language competence and communicative language activity, which is expressed in the form of the "Japan Foundation standards tree."

The social order for knowledge of the Japanese language was formed in the context of the international cooperation intensification with the countries of the Asia-Pacific region in the Republic of Sakha (Yakutia) for the implementation of effective communication in the political, socio-economic, cultural, scientific, and educational spheres. The development of close ties with Japan is one of the priority areas of international cooperation of the Republic of Sakha (Yakutia) for the implementation of strategic plans for the northern region development.

\section{Materials and methods}

The problem of the Japanese language teaching is included in the scientific interest range of the following researchers:

- cultural approach to teaching as a second foreign language [Ivanova N.S.];
- initial stage of teaching a monologue in Japanese [Maksimenko N.L.];

- teaching a second foreign language in the context of functional multilingualism [Molchanova L.V.];

- teaching the main foreign language (Japanese) to bilingual students [Efimova S.K.];

- structure and content of Japanese textbooks for Russian speakers [Nechaeva L.T.];

- typology of difficulties in learning Japanese at the initial stage [Son I.S.].

Nowadays, special attention is paid to the functioning of communicative competence in the framework of the issues of teaching Japanese language to students of a language university. The JF standard was developed on the basis of the CEFR Common European Framework of Reference (CEFR). The Common European Framework of References consists of 6 generally accepted levels of knowledge and skills of learners, from the simplest A1 to the most complicated $\mathrm{C} 2$, as well as explanations (Can do) for each level [2]. The sentences are structured according to the principle: what topics the student "can/is able" to develop applying a foreign language.

The comparative analysis has showed that 493 Cando formulations are represented in the common European competences, 552 - in the Japan Foundation standard, Can-do tables are used as a scoring system. Moreover, much attention is paid to the grading system for various parameters: content, grammar, pronunciation, etc. Students evaluate each other and themselves according to the "jikou hyouka" system「自己評価, independently track their progress in language learning. Communicative language competencies in accordance with the Japan Foundation Standard contain levels from A1 to B1. B2 level will be added soon.

Corresponding author: zbstepanova@mail.ru 

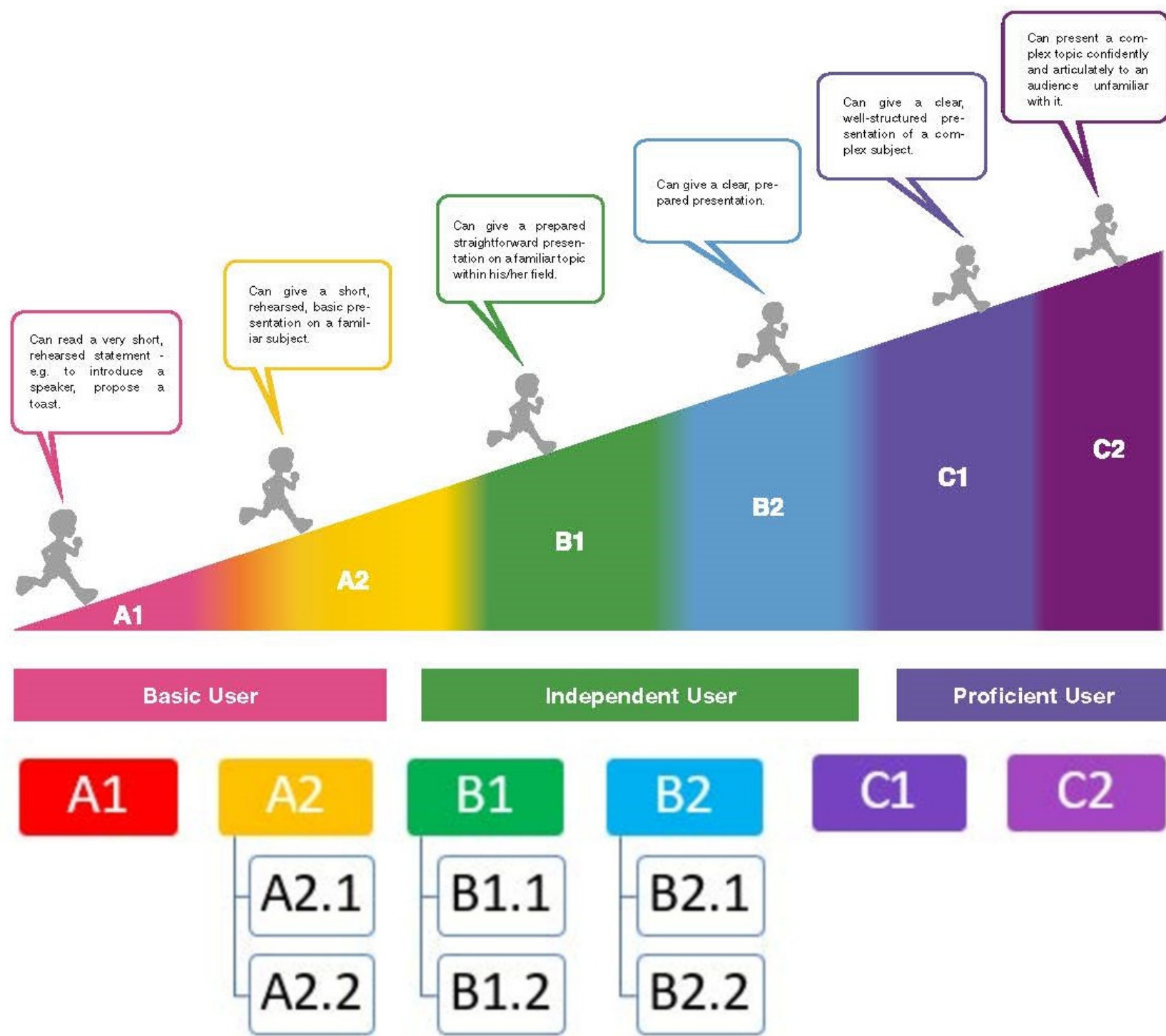

Independent User

Proficient User

Fig. 1 JF standard levels.

It is possible to determine the level of language proficiency due to the transcripts of the "Can-do" competency statements that form the basis of the JF Standard, namely, what students should perform in Japanese and at what level. They can be applied in planning practical sessions, developing teaching materials and assessing knowledge.

"Japan Foundation Standard Tree", which linked such basic parameters as communicative language activity and communicative language competence, was first published in 2010. The given tree of standards reflects the relationship between communication skills in a foreign language and speech activity [3]. 


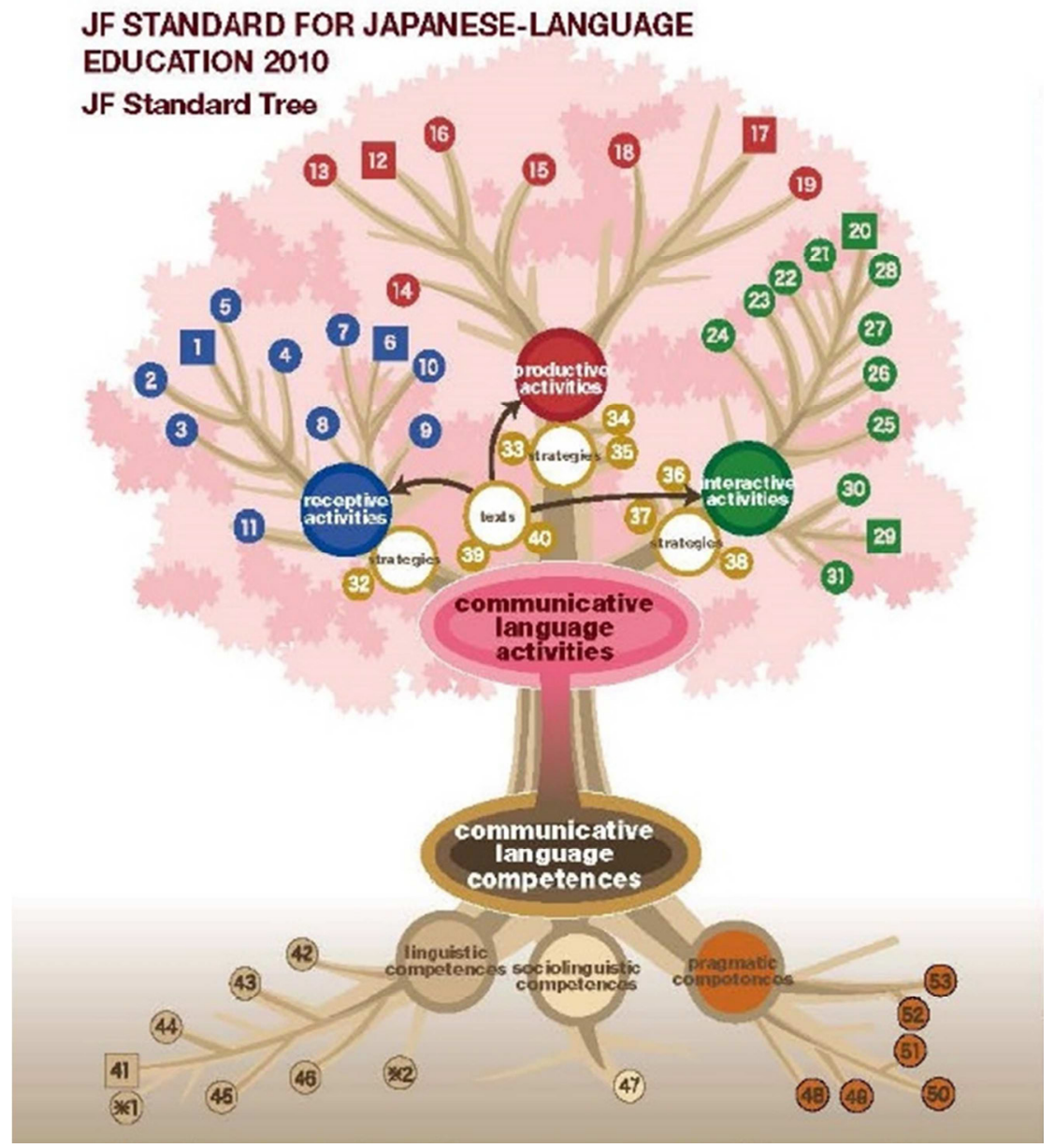

Fig.2 Japan Foundation Standard Tree.

There are 53 categories in total - the roots and branches of the JF Standard Tree. Communicative language competence is presented in the form of the tree roots, and consists of three main competencies: linguistic (vocabulary, grammar, pronunciation, writing, etc.), sociolinguistic (using language in accordance with the relationship with the speaker and the situation), pragmatic (building a discussion, conducting a conversation, using the language consciously) [4].

Linguistic competence has been studied for a long time in teaching methods and consists of six categories in the JF standard: general language proficiency, proficiency at the lexical level, use of vocabulary, proficiency at the grammatical level, proficiency at the phonemic level, proficiency at the spelling level. Semantic and orthopoetic sub-competencies are separately identified in the linguistic competence, they are under development and have not been included in the Can-do list yet. Sociolinguistic competence represents the appropriate use of language in a sociolinguistic context. Pragmatic competence is represented in discursive and functional sub-competencies. Discursive subcompetence is expressed in general flexibility, dialogue, topic development, brevity, and coherence. Functional sub-competence deals with narrative clarity and fluency, that is the correct use of language in communication, depending on the statement purpose.
Linguistic competence is formed in linguistic activity in a specific communicative situation, both in teaching a language and in applying it. Linguistic activity is carried out using linguistic competencies, strategies and texts that are aimed at the effective use of the mentioned competencies. In the JF Standard Tree, the roots (communicative language competence) support communicative language activity, consisting of three main activities: receptive, productive and interactive, which in turn are overgrown with 40 branches (categories). Receptive activity is expressed in the information perception (the ability to read, listen, etc.). Productive activity involves the information reproduction (the ability to speak and write independently). Interactive activity, in turn, implies the information exchange (dialogue, letters, etc.).

"Texts" are singled out separately as a category in the tree due to the fact that linguistic activity and linguistic competence closely interact with each other. Linguistic activity can hardly be attributed to the above activities, for example, writing notes or statements. Texts serve as a link between two aspects - perception and reproduction.

Communication strategies that link them to linguistic competencies are presented in each type of linguistic activity. They explain how best to apply language competence in order to effectively carry out speech activities. The following strategies are highlighted in 
productive activity: utterance planning, compensating in other ways, checking and editing. The strategy for building written or oral assumptions is presented in receptive activity. Strategies for conducting a dialogue in turn, active participation in the discussion development, requests for additional explanations are isolated in interactive activities.

Generally, the JF Standard Tree simplifies the learning goal comprehension, needs of various students, and suggests focusing on the study of parts of branches and roots, thus contributing to the construction of an individual educational trajectory in teaching Japanese.

\section{Results and Discussion}

JF standard defines the ability to perform tasks from A1 to C2 [5]. The sentence "Can-do" means "what and how much you can do in Japanese" at each level. For instance, there are the following "Can-do" in the case of language activity "communicative interaction" for each level.

A1: You can exchange simple greetings with friends and neighbors depending on the day time.

A2: You can welcome a friend's family at his home and briefly, in simple words, talk about your current situation.

B1: You can talk to a friend's family at his home about your current situation, including your feelings.

B2: You can talk to friends and coworkers about your relationships, dissatisfaction and satisfaction with your relationships and work, highlighting what is important to you.

The JF standard consists of both the CEFR Can-dos and the JF Can-dos standard. CEFR Can-dos are multipurpose abstract descriptors, while JF Can-dos are examples of practical action language related to communication situations in Japanese.

It is essential to study not only the language in the JF standard, but also the culture in order to deepen intercultural comprehension. The standard allows not only becoming familiar with various cultures, but also develops a perspective to reflect on our culture.

As noted by Tikako Sigemori and other Japanese researchers, the goals of the JF standard for the development of reading and writing skills are spelled out in more detail. Knowledge of the Japanese language cannot be assessed in the same way as in the case of European languages: Japanese does not belong to the Indo-European languages and languages with a nonLatin alphabet, which requires much more effort and time from students to learn Japanese. The reasons for the granularity of the JF standard versus the CEFR are the complexity of the Japanese writing system and the diverse courtesy strategies of the Japanese, which require various sets of expressions to point out the same meaning in different social situations.

The standard is recommended to be used both for individual planning and for the development of language courses and textbooks, teaching materials, tests and exams, and etc. To this end, JF has created a website named "Minna no Can-do" [Minnanokyozai]. The given materials can be used to plan classes and create assignments for students. They, in turn, can apply the site to assess their language skills. The database includes very detailed and specific descriptions of classes, depending on the type of student and their purpose.

Can-do is divided into three types. CEFR Can-do has 493 formulations for six levels (A1-C2), which have general linguistic descriptions applicable to any language. JF Can-do has 552 formulations for four levels (A1-B2) directly for communication in Japanese, created independently of the CEFR formulations. "Minna no Can-do" users can create own Can-do formulations based on CEFR Can-do and JF Can-do.

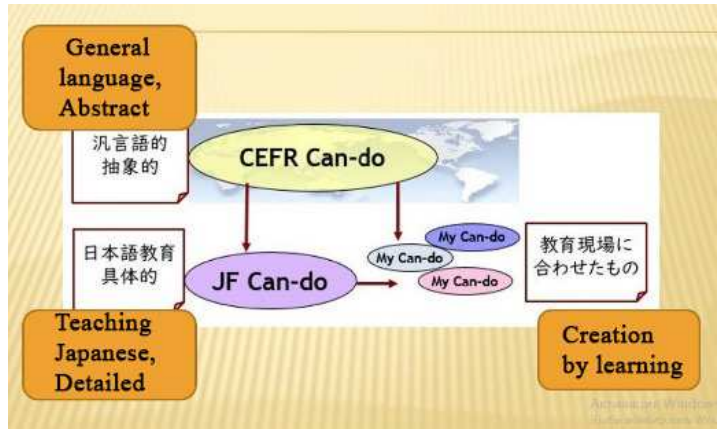

Fig.3 Creating My Can-do

The CEFR Can-do and JF Can-do featured on the "Minna no Can-do" website can be applied as they appear in every teaching situation. It is also possible to create a new Can-do that suits every situation. A new Can-do created by the user for each situation is called MY Can-do. By creating MY Can-do, you can flexibly set goals for various educational situations.

JF has developed a portfolio as a grading system through which the learner can store material for reflection on their learning. Students independently assess their Japanese language skills, record their language and cultural experience, collect the materials and store them in portfolios. Based on the given materials, they can monitor own learning process and learning outcomes.

A portfolio has a number of advantages:

- teacher and learner can share learning goals and learning processes;

- when a student moves to another educational institution, the opportunity to accurately convey the learning outcomes up to this point has been taken into account;

- recording self-assessment and experience, learners can improve their ability to complete tasks and comprehend intercultural communication as well as autonomous learning and learning motivation;

- students can assess not only their abilities, but also the results of learning various knowledge and skills acquired during the lesson and outside it.

It is significant that the student records and presents their learning process in a structure and format which are easy to save and can be repeated for use as a portfolio as an assessment system in Japanese teaching methodology. Thus, the portfolio in the JF standard is considered in conjunction with the following three components: 
"scoring table", "record of language and cultural experience" and "learning outcomes."

The pedagogical application conditions of the portfolio include:

- creation of flexible design in accordance with the age of the target audience, pedagogical goals and objectives. Consideration of the components connection, general structure and the file format development so that it is easy to apply in every situation.

- teacher must carefully study the criteria for evaluating educational activities and reuse them for improvement, authenticity, and reliability.

- Reflections on learning outcomes are not only left to the learner, but are also included as activities within the course. The ability to learn autonomously continues to develop, providing an opportunity to reflect with the instructor and fellow students.

Therefore, it is necessary to significantly develop a portfolio that corresponds to the goal and content of the educational process, forms the required competencies, makes improvements, taking into consideration the pedagogical merits. The formation of communicative competence, which provides comfortable conditions for cognitive activity and further self-improvement, occurs as a result of the given technology application.

The Japan foundation has developed two educational complexes "Marugoto" and "Irodori" based on the JF standard.

"Marugoto" is an active, dynamic textbook that includes a large amount of information about Japanese culture, designed to motivate a wide variety of learners to learn the language. The given study guide has been worked out for those who study Japanese outside of Japan but are interested in it. It has been designed so that listeners can also experience Japanese culture while learning the language. Two textbooks "Katsudo" and "Rikai" are included in the "Marugoto" series. The textbook "Katsudo" ("practice") is intended for mastering communication skills [6]. Japanese culture is studied with its help, as well as the Japanese language use in specific situations and for specific purposes. "Rikai" ("comprehension") is a textbook for studying the language structure (writing, grammar, vocabulary) [7]. The "Marugoto Plus" website, where users can improve their Japanese language skills (beginner and intermediate levels), is based on the content of "Marugoto: Japanese language and culture."

"Irodori" is a textbook designed for international students to learn basic Japanese communication skills required for everyday life and work in Japan [8]. The textbook aims to develop the conversational skills of the Japanese language through audio materials. Moreover, the student can get acquainted with Japanese life and culture, through the multiplicity of topics presented in the textbook. The purpose of this tutorial is to teach learners how to use Japanese when communicating in real life. All PDF materials and MP3 audio files are available online.

\section{Conclusion}

Presently, much attention is paid to the communication competence and communication activities of the student when teaching Japanese. This means that any material for those who study Japanese, as well as any other foreign language, must be accompanied with cultural explanations and clarifications, visibility or video clip, brochure, photograph and even a real subject.

Generally, Japanese language teaching methodology tries to integrate the most efficient methods and technologies. The JF standard defines the mastery of students' communication skills as a priority goal in learning Japanese. It is required to have an idea of the Japanese lifestyle, their traditions and customs in order to communicate in Japanese.

\section{References}

1. JF nihongo kyouiku sutandato. Riyousha no tame no gaidobukku. (Japan Foundation, 2017)

2. Common European Framework of Reference for Languages: Learning, teaching, assessment (Council of Europe, 2001)

3. D.S. Lazareva On new approaches in Japan to teaching Japanese as a foreign language, In Japanese language. Japanese language teaching method, pp. 71-77. (Moscow: HSE, 2010).

4. A.S. Shimanskaya Modern approaches to teaching Japanese as a foreign language, MSLU Bulletin. Education and pedagogical sciences, 3 (802), 128-138, (2018).

5. H. Kijima, T. Shibahara, N. Hatta JF nihongo kyouiku sutandato junkyo kosubukku no kaihatsu, Kokusai kouryuu kikin nihongo kyouiku kiyou. 8, 103-117, (2012).

6. Marugoto Nihon no kotoba to bunka. Nyuumon Al Katsudou. (Japan Foundation, 2013)

7. Marugoto Nihon no kotoba to bunka. Nyuumon A1. Rikai. (Japan Foundation, 2013)

8. Irodori. Seikatsu no nihongo. Nyuumon Al. (Japan Foudation, 2013) 